\title{
Quality of life and its associated factors among patients with COPD before and after an exacerbation in Sri Lanka
}

\author{
PKB Mahesh ${ }^{1 *}$, Wasantha Gunathunga ${ }^{2}$, Saroj Jayasinghe ${ }^{3}$, Mahendra Arnold ${ }^{1}$, Vajira Croos ${ }^{1}$, \\ Sinha De Silva ${ }^{4}$ \\ ${ }^{1}$ Office of the Regional Director of Health Services, Colombo, Sri Lanka; ${ }^{2}$ Department of Community Medicine, Faculty \\ of Medicine, University of Colombo, Sri Lanka; ${ }^{3}$ Department of Clinical Medicine, Faculty of Medicine, University of \\ Colombo, Sri Lanka; ${ }^{4}$ Postgraduate Institute of Medicine, University of Colombo \\ *Correspondence: buddhikamaheshpk@gmail.com (1D https://orcid.org/0000-0002-9037-5142
}

DOI: https://doi.org/10.4038/jccpsl.v24i2.8146

Received on: 07 April 2018

Accepted on: 28 June 2018

\begin{abstract}
Background: With demographic and epidemiological transitions, the burden of chronic non-communicable diseases (NCDs) is rising in Sri Lanka. Chronic obstructive pulmonary disease (COPD) is one main chronic NCD, the exacerbations of which are known to worsen the quality of life (QOL). Documented literature on the QOL of COPD patients is not commonly found in Sri Lanka and rarer on its exacerbations.
\end{abstract}

Objective: To describe the QOL and its associated factors among patients with COPD before and after an exacerbation in Western Province of Sri Lanka

Methods: A longitudinal study with two waves of data collection was done in 13 government hospitals among 289 participants in 2015. The study population included patients admitted to hospital with an exacerbation of COPD. Sample size was calculated to estimate the expected QOL in numerical scale with reference to documented global literature. The pre-exacerbation and post-discharge one month QOL was assessed using SF-36 generic QOL tool. Bivariate analysis was done followed by multivariate analysis.

Results: In seven domains, there was a significant decline in QOL from pre-exacerbation to one month postdischarge $(\mathrm{p}<0.05)$. Further, pre-exacerbation QOL significantly correlated with post-discharge QOL in relation to five domains. Age (two domains), income (seven domains) and health infrastructure (seven domains) were significantly associated with their pre-exacerbation QOL. Younger age, higher income and better health-infrastructure are associated with relatively higher baseline. Older age, higher monthly income, better health infrastructure and less severity of the exacerbation were independent predictors of reduced QOL following an exacerbation.

Conclusions: The QOL among COPD patients was relatively low compared to patients with other chronic NCDs such as myocardial infarction and stroke. The QOL in relation to several aspects worsened with exacerbations. Post-discharge QOL can be predicted with pre-exacerbation QOL for five domains of QOL.

Key words: quality of life, exacerbation, chronic respiratory disease, chronic obstructive pulmonary disease 


\section{Introduction}

Chronic obstructive pulmonary disease (COPD) is an umbrella term representing a group of pathologies with airway limitation (1). It is estimated that around 328 million people suffer from COPD worldwide while some literature even point towards a higher figure (2). Its prevalence varies across the world (3) and incurs a significant cost to the health systems of countries (4). Exacerbations of COPD are worsening episodes of the symptoms, which are associated with unfavourable outcomes (5-6). Patients with moderatesevere COPD may even get more than three exacerbations per year (7).

Sri Lanka through its free healthcare services has achieved significantly improved health parameters (8). With the recent demographic and epidemiological transition, the inhabitants have been more vulnerable to chronic NCDs, accounting for $50 \%$ of the total disability adjusted life years (9). Chronic respiratory diseases remain as one of the main four NCD entities in Sri Lanka (10).

Quality of life (QOL) is a composite concept that reflects the perception of an individual's position within the living context (11). COPD interferes with the lifestyle causing physical, functional, social and emotional limitations lowering the QOL $(7,12)$. Thus, new approaches which include health-related QOL and personalized elements have been introduced to assess the success of management of COPD (13). With exacerbations, the QOL of COPD patients is expected to further decline (14). Such documented literature based on Sri Lanka is rare on COPD, particularly on their QOL. Exploring the baseline QOL among COPD patients, its change following an exacerbation and the predictors would help in development of clinical policies. Furthermore, it would be an initial step in developing predictive models for the change of QOL following an exacerbation.

There are many tools which describe QOL (15) of which Short Form-36 (SF-36) is a generic tool. It provides eight domain scores in relation to general health, physical functioning, pain, role limitation due to physical problems, social functioning, vitality, role limitations due to emotional problems and mental health. These eight domains can be further summarized into two main entities as 'physical' and 'mental' (16). SF36 has been validated for several disease conditions in Sri Lanka (17-18). Its validity and reliability in relation to COPD patients has been proven by many studies
(19-20). The objective of this study was to describe the QOL and its associated factors among patients with COPD before and after an exacerbation in Western Province, Sri Lanka.

\section{Methods}

A longitudinal study was conducted with two waves of data collection. The first wave was hospitalbased, while the second was based on a postal mail follow-up. Participants were recruited from 13 state hospitals with secondary and tertiary care facilities in the Western Province, Sri Lanka. This province represents approximately $30 \%$ of the Sri Lankan population with highest population density (1600 people per $\mathrm{km}^{2}$ ) and the most number of secondary and tertiary care hospitals in Sri Lanka (21). The study population comprised patients above the age of 16 years who had been followed up for COPD and were admitted to hospital with an exacerbation. The diagnosis of COPD of the participants had been made at least one month back, considering the spirometer findings (FEV1/FVC ratio less than $70 \%$ and post-bronchodilator FEV1 reversibility less than 15\%) or in the absence of spirometry, other clinical features as recommended by the World Health Organization (22). The latter diagnostic method is acceptable, as spirometric assessments are routinely available in only some of the hospitals. Exclusion criteria included participants with comorbid conditions which would impose a potential direct impairment of their QOL, such as persons with amputation, having paralysis or diagnosed with a psychotic condition. Furthermore, patients with a hospital stay of less than 48 hours were excluded.

Sample size was calculated using the highest standard deviation values in documented literature. With an assumed response rate of $80 \%$ and design effect of 2 at $5 \%$ significance level, the sample size needed was 276 (3, 23-24). Data collection was done from January to March 2015, having started simultaneously in all study settings on 1st of January. All patients satisfying the eligibility criteria were recruited.

Initial data collection was done in hospital by four trained pre-intern medical graduates, using a pre-tested interviewer-administered questionnaire and a data extraction sheet. The latter form extracted medical details from the hospital records, including the severity of COPD as graded by the scale of Burge and Wedzicha (7). The questionnaire included the socio-demographic details, health infrastructure related details and the SF- 
36 QOL measuring tool. A validated tool was used to quantify the health infrastructure based on availability, accessibility and affordability of health services with a maximum possible score of 5 (25-27). The SF-36 was administered to assess the baseline QOL (i.e. preexacerbation QOL), by asking participants to focus on the 28 day period preceding the exacerbation.

Out of the 36 questions in SF-36, 35 items were assessed on eight domains as recommended $(16,27)$. The QOL scores for each domain ranged from 0 to 100. General health domain included five items, each with five responses to explore the perception on personal health. Physical functioning domain assessed the limitations of physical activities due to health. It included 10 items, each with three responses. Role limitation-physical included four items (each with two responses) and assesses the problems with daily activities as a result of physical issues. Pain domain included two items (one with six responses and the other with five responses) and explores the presence of pain or any limitation due to pain. Three items with two responses were included in the role limitationemotional domain which assesses the problems with daily activities as a result of emotional issues. Vitality domain included four items with six responses and describes the level of energy and the level of being worn out. Social functioning domain included two domains to assess the level of interference of physical or emotional problems on social activities. Mental health domain included five items (each with six responses) and explores the feelings like happiness, peacefulness and calmness.

At the hospital discharge, a stamped envelope was given to the participants with the written postal address of the principal investigator. It included the SF-36 QOL tool to be completed at one month following the hospital discharge. The participants were given a reminder at 28 days following the hospital discharge over the phone to fill it. Ethics approval was obtained from the Ethics Review Committee of Sri Lanka Medical Association as well as from the Medical Research Institute. Informed written consent was obtained from the participants.

\section{Data analysis}

Since the study included pre- and post-QOL evaluations, only the participants with both parameters were included in the data analysis. Potential nonresponse bias was analysed by comparing the characteristics of responders and non-responders.
Associations between pre-exacerbation and postdischarge QOL were evaluated using statistical tests at 5\% significance level. The associations of age, gender, income and health-infrastructure were evaluated with both pre-exacerbation and the change in QOL scores following hospital discharge. Additionally, association of the severity of exacerbation was evaluated with the change in QOL. For categorical factors, Mann Whitney $\mathrm{U}$ test was used and for the numerical factors Spearman rho was used. The comparison of pre-exacerbation and post-discharge was done with Wilcoxon signed rank test (28). Factors significantly associated with each domain of SF-36 QOL at p value less than 0.2 were included as independent variables in the logistic regression models. This was done to make sure that important variables are not omitted due to the confounding effect of other variables. The dependent variable was dichotomized as reduced QOL following the exacerbation and not.

\section{Results}

Of the recruited participants, 289 questionnaires were received by post. The response rate for this postdischarge questionnaire was 84\%. Age $(p=0.31)$, gender $(p=0.87)$, severity of exacerbation $(p=0.22)$, duration of stay $(p=0.74)$, level of health infrastructure $(p=0.07)$ and baseline QOL scores of seven out of eight domains of SF-36 ( $>0.05$ ) did not show any significant difference between responders and nonresponders. The only exception was role limitation emotional domain $(\mathrm{p}=0.04)$.

The median age of respondents was 65 (interquartile range (IQR): 57 to 72 years). Majority ( $n=269$, 93\%) were males and had completed primary education $(n=245,85 \%)$. Nearly half of the participants (48\%) had an average monthly income less than Rs. 20,000. Nearly 20\% ( $n=57)$ had diabetes, 32\% (n=91) had hypertension and 13.5\% $(n=39)$ had hypercholesterolemia. The median duration of hospital stay was 6 (IQR=5 to 8) days. The median score obtained for health infrastructure was 1.5 ( $\mathrm{IQR}=0.75$ to 1.75 ) and 2 (1 to 2 ) for the severity of exacerbation.

Table 1 compares the pre-exacerbation QOL with post-discharge QOL. Role limitation domains showed the lowest QOL scores. Within all eight domains, the post-discharge median QOL scores were lower than the pre-exacerbation scores. Except pain domain, all other domains showed a significant difference. Except pain and role limitation domains, all other five domains 
showed significant positive correlations between preand post-QOL scores, even though the strength of associations was poor $(\mathrm{r}<0.3)$.

Associations of the pre-exacerbation QOL are shown in Table 2 . The age was significantly associated with only physical functioning $(\mathrm{p}<0.001)$ and social functioning $(\mathrm{p}=0.03)$ domains; income with seven domains; and health infrastructure with all eight domains. There was no significant relationship observed with gender $(\mathrm{p}>0.05)$.

Table 3 shows the relationship of the change of baseline QOL following the exacerbation with five potential associated factors. Gender was not associated with the change of QOL ( $>00.05)$. To the contrary, age (for five domains), income (for three domains), health infrastructure (for six domains) and severity of the exacerbation (for three domains) showed significant associations with the change in QOL.

Table 4 demonstrates the findings of the multivariate analysis on the predictors of post-discharge QOL. Older age was significantly associated with lowering of the QOL than the baseline following exacerbation in the general health, vitality, social functioning and mental health domains. Better health infrastructure was associated with a reduction of postdischarge QOL for general health, physical functioning, role limitation-physical and emotional, social functioning and mental health domains. A higher monthly income was associated with a lowered QOL for physical functioning and role limitation-physical domains. Less severity of COPD was associated with a lowered QOL for physical functioning, pain, role limitation-physical, social functioning and mental health domains.

Table 1. Comparison of the pre-exacerbation and post-discharge QOL of COPD patients ( $N=289)$

\begin{tabular}{|c|c|c|c|c|}
\hline \multirow[t]{2}{*}{ Domain } & \multicolumn{2}{|c|}{ QOL, Median (IQR) } & \multirow{2}{*}{$\begin{array}{l}\text { Correlation }^{1} \\
\text { Significance }\end{array}$} & \multirow{2}{*}{$\begin{array}{l}\text { Significance of } \\
\text { the difference }\end{array}$} \\
\hline & Pre-event & Post-discharge & & \\
\hline General-health & $\begin{array}{r}30.0 \\
(20.0-45.0)\end{array}$ & $\begin{array}{r}20.0 \\
(10.0-30.0)\end{array}$ & $\begin{array}{r}r=0.26 \\
p<0.001\end{array}$ & $\mathbf{p}<\mathbf{0 . 0 0 1}$ \\
\hline Physical functioning & $\begin{array}{r}35.0 \\
(10.0-65.0)\end{array}$ & $\begin{array}{r}35.0 \\
(20.0-55.0)\end{array}$ & $\begin{array}{r}r=0.29 \\
p<0.001\end{array}$ & $\mathrm{p}=\mathbf{0 . 0 0 2}$ \\
\hline Pain & $\begin{array}{r}55.0 \\
(35.0-77.5)\end{array}$ & $\begin{array}{r}51.3 \\
(32.5-77.5)\end{array}$ & $\begin{array}{l}r=-0.03 \\
p=0.65\end{array}$ & $\mathrm{p}=0.11$ \\
\hline Role limitation physical & $\begin{array}{r}0.0 \\
(0.0-100.0)\end{array}$ & $\begin{array}{r}0.0 \\
(0.0-0.0)\end{array}$ & $\begin{array}{l}r=-0.06 \\
p=0.33\end{array}$ & $\mathbf{p}<0.001$ \\
\hline Role limitation emotional & $\begin{array}{r}0.0 \\
(0.0-100.0)\end{array}$ & $\begin{array}{r}0.0 \\
(0.0-0.0)\end{array}$ & $\begin{array}{r}r=0.01 \\
p=0.92\end{array}$ & $\mathbf{p}<0.001$ \\
\hline Vitality & $\begin{array}{r}45.0 \\
(30.0-50.0)\end{array}$ & $\begin{array}{r}35.0 \\
(20.0-50.0)\end{array}$ & $\begin{array}{r}r=0.26 \\
p<0.001\end{array}$ & $\mathrm{p}<0.001$ \\
\hline Social functioning & $\begin{array}{r}62.5 \\
(37.5-75.0)\end{array}$ & $\begin{array}{r}62.5 \\
(37.5-75.0)\end{array}$ & $\begin{array}{l}r=0.12 \\
p=0.05\end{array}$ & $p=0.05$ \\
\hline Mental health & $\begin{array}{r}52.0 \\
(40.0-60.0)\end{array}$ & $\begin{array}{r}48.0 \\
(36.0-56.0)\end{array}$ & $\begin{array}{r}r=0.19 \\
p=0.003\end{array}$ & $\mathbf{p}<\mathbf{0 . 0 0 1}$ \\
\hline
\end{tabular}

${ }^{1}$ Correlation assessed using Spearman-correlation coefficient (r)

${ }^{2}$ Significance assessed using Mann-Whitney U test

Significant associations at 0.05 level given in bold letters 
Table 2. Factors associated with the pre-exacerbation QOL of COPD patients $(\mathbf{N}=\mathbf{2 8 9})$

\begin{tabular}{|c|c|c|c|c|}
\hline Domain & Age $^{1}$ & Gender $^{2}$ & Income $^{1}$ & $\begin{array}{r}\text { Health care } \\
\text { system }^{1}\end{array}$ \\
\hline General health & $\begin{array}{l}r=-0.07 \\
p=0.24\end{array}$ & $\mathrm{p}=0.41$ & $\begin{array}{r}r=0.22 \\
p<0.001\end{array}$ & $\begin{array}{r}r=0.25 \\
p<0.001\end{array}$ \\
\hline Physical functioning & $\begin{array}{l}r=-0.22 \\
p<0.001\end{array}$ & $\mathrm{p}=0.07$ & $\begin{array}{r}r=0.37 \\
\mathbf{p}<0.001\end{array}$ & $\begin{array}{l}r=0.19 \\
p=0.01\end{array}$ \\
\hline Pain & $\begin{array}{l}\mathrm{r}=-0.07 \\
\mathrm{p}=0.25\end{array}$ & $\mathrm{p}=0.45$ & $\begin{array}{r}r=0.33 \\
p<0.001\end{array}$ & $\begin{array}{l}r=0.18 \\
p=0.01\end{array}$ \\
\hline Role limitation-physical & $\begin{array}{l}r=-0.11 \\
p=0.05\end{array}$ & $\mathrm{p}=0.37$ & $\begin{array}{r}r=0.31 \\
p<0.001\end{array}$ & $\begin{array}{l}r=0.15 \\
p=0.02\end{array}$ \\
\hline Role limitation-emotional & $\begin{array}{l}r=-0.04 \\
p=0.55\end{array}$ & $\mathrm{p}=0.52$ & $\begin{array}{l}r=0.13 \\
p=0.03\end{array}$ & $\begin{array}{r}r=0.22 \\
p<0.001\end{array}$ \\
\hline Vitality & $\begin{array}{r}r=0.01 \\
p=0.95\end{array}$ & $\mathrm{p}=0.55$ & $\begin{array}{r}r=0.28 \\
p<0.001\end{array}$ & $\begin{array}{r}r=0.26 \\
p<0.001\end{array}$ \\
\hline Social functioning & $\begin{array}{r}r=-0.13 \\
p=0.03\end{array}$ & $\mathrm{p}=0.54$ & $\begin{array}{r}r=0.33 \\
p<0.001\end{array}$ & $\begin{array}{r}r=0.19 \\
p=0.001\end{array}$ \\
\hline Mental health & $\begin{array}{l}r=-0.04 \\
p=0.53\end{array}$ & $\mathrm{p}=0.99$ & $\begin{array}{r}r=0.09 \\
p=0.12\end{array}$ & $\begin{aligned} r & =-0.26 \\
p & <0.001\end{aligned}$ \\
\hline
\end{tabular}

${ }^{1}$ Correlation assessed using Spearman-correlation coefficient (r) ${ }^{2}$ Significance assessed using Mann-Whitney U test Significant associations at 0.05 level given in bold letters

Table 3. Associations of the change of QOL from the baseline among COPD patients $(\mathrm{N}=\mathbf{2 8 9})$

\begin{tabular}{|c|c|c|c|c|c|}
\hline Domain & Age $^{1}$ & Gender $^{2}$ & Income $^{1}$ & $\begin{array}{r}\text { Health care } \\
\text { system }^{1}\end{array}$ & Severity \\
\hline \multirow[t]{2}{*}{ General health } & $r=0.13$ & $\mathrm{p}=0.2$ & $\mathrm{r}=0.02$ & $\mathrm{r}=0.2$ & $r=-0.08$ \\
\hline & $p=0.04$ & & $\mathrm{p}=0.78$ & $p=0.002$ & $\mathrm{p}=0.18$ \\
\hline \multirow[t]{2}{*}{ Physical functioning } & $\mathrm{r}=0.06$ & $\mathrm{p}=0.38$ & $\mathbf{r}=0.23$ & $r=0.16$ & $r=-1.17$ \\
\hline & $\mathrm{p}=0.33$ & & $\mathbf{p}<\mathbf{0 . 0 0 1}$ & $\mathrm{p}=\mathbf{0 . 0 1}$ & $\mathrm{p}=\mathbf{0 . 0 0 5}$ \\
\hline \multirow[t]{2}{*}{ Pain } & $r=0.22$ & $\mathrm{p}=0.46$ & $\mathrm{r}=0.11$ & $\mathrm{r}=0.12$ & $r=-0.15$ \\
\hline & $\mathrm{p}=\mathbf{0 . 0 0 1}$ & & $\mathrm{p}=0.07$ & $\mathrm{p}=0.06$ & $\mathrm{p}=\mathbf{0 . 0 2}$ \\
\hline \multirow[t]{2}{*}{ Role limitation-physical } & $r=-0.08$ & $\mathrm{p}=0.96$ & $r=0.18$ & $\mathrm{r}=0.11$ & $\mathrm{r}=-0.11$ \\
\hline & $\mathrm{p}=0.23$ & & $p=0.004$ & $\mathrm{p}=0.09$ & $\mathrm{p}=0.08$ \\
\hline \multirow[t]{2}{*}{ Role limitation-emotional } & $r=-0.04$ & $\mathrm{p}=0.47$ & $\mathrm{r}=0.01$ & $r=0.19$ & $r=-0.06$ \\
\hline & $\mathrm{p}=0.52$ & & $\mathrm{p}=0.88$ & $p=0.003$ & $\mathrm{p}=0.34$ \\
\hline \multirow[t]{2}{*}{ Vitality } & $r=0.31$ & $\mathrm{p}=0.47$ & $\mathrm{r}=0.01$ & $r=0.13$ & $r=-0.04$ \\
\hline & $\mathrm{p}<0.001$ & & $\mathrm{p}=0.96$ & $\mathbf{p}=\mathbf{0 . 0 5}$ & $\mathrm{p}=0.56$ \\
\hline \multirow[t]{2}{*}{ Social functioning } & $r=0.17$ & $\mathrm{p}=0.99$ & $r=0.15$ & $r=0.14$ & $\mathrm{r}=-0.12$ \\
\hline & $p=0.01$ & & $p=0.01$ & $p=0.04$ & $\mathrm{p}=0.06$ \\
\hline \multirow[t]{2}{*}{ Mental health } & $r=0.19$ & $\mathrm{p}=0.87$ & $\mathrm{r}=0.02$ & $r=0.25$ & $r=-0.15$ \\
\hline & $p=0.002$ & & $\mathrm{p}=0.81$ & $\mathrm{p}<0.001$ & $p=0.02$ \\
\hline
\end{tabular}

${ }^{1}$ Correlation assessed using Spearman-correlation coefficient (r) $\quad{ }^{2}$ Significance assessed using Mann-Whitney U test Significant associations at 0.05 level given in bold letters 
Table 4. Independent predictors of the post-hospital discharge QOL of COPD patients(N=289)

\begin{tabular}{|c|c|c|c|}
\hline Domain & $\begin{array}{l}\text { Variables in the } \\
\text { model }\end{array}$ & $\begin{array}{l}\text { Adjusted } \\
\text { Odds Ratio }\end{array}$ & $95 \% \mathrm{CI}$ \\
\hline \multirow[t]{3}{*}{ General health } & Age & 1.03 & $1.01-1.06$ \\
\hline & Health infrastructure & 1.35 & $1.02-1.99$ \\
\hline & Severity & 0.68 & $0.45-1.02$ \\
\hline \multirow[t]{3}{*}{ Physical functioning } & Income & 1.32 & $1.02-1.69$ \\
\hline & Severity & 0.66 & $0.44-0.99$ \\
\hline & Health infrastructure & 1.46 & $1.06-1.99$ \\
\hline \multirow[t]{4}{*}{ Pain } & Severity & 0.51 & $0.32-0.79$ \\
\hline & Age & 1.01 & $0.99-1.03$ \\
\hline & Health infrastructure & 0.99 & $0.74-1.35$ \\
\hline & Incom & 0.95 & $0.75-1.21$ \\
\hline \multirow[t]{3}{*}{ Role limitation-physical } & Income & 1.41 & $1.08-1.83$ \\
\hline & Severity & 0.52 & $0.29-0.93$ \\
\hline & Health infrastructure & 1.51 & $1.06-2.15$ \\
\hline Role limitation-emotional & Health infrastructure & 1.43 & $1.06-1.94$ \\
\hline \multirow[t]{2}{*}{ Vitality } & Age & 1.07 & $1.04-1.10$ \\
\hline & Health infrastructure & 1.08 & $0.79-1.47$ \\
\hline \multirow[t]{4}{*}{ Social functioning } & Severity & 0.64 & $0.41-0.98$ \\
\hline & Age & 1.03 & $1.01-1.05$ \\
\hline & Health infrastructure & 1.41 & $1.03-1.92$ \\
\hline & Income & 0.99 & $0.78-1.26$ \\
\hline \multirow[t]{3}{*}{ Mental health } & Age & 1.05 & $1.02-1.08$ \\
\hline & Severity & 0.51 & $0.31-0.82$ \\
\hline & Health infrastructure & 1.48 & $1.07-2.03$ \\
\hline
\end{tabular}

Significant associations at 0.05 level given in bold letters

\section{Discussion}

The present study was done to explore the preand post-exacerbation QOL and their associated factors among patients with COPD. Findings of this study point towards low QOL of patients with COPD worsening following an exacerbation, compared to other chronic NCDs such as myocardial infarction and stroke (25, 26-27). Older age, better health infrastructure, higher income and lower severity of the exacerbation are associated with a reduction of QOL compared to the baseline. Pre-exacerbation QOL is significantly correlated with the post-discharge QOL in five domains.

Comorbid NCDs were commonly seen in the study participants, which is in par with the global findings on COPD (28). This would have contributed to the relatively lower QOL scores and reflects the value of having a comprehensive NCD management policy. Exclusion of conditions which would directly influence the QOL refined the associations studied. The present study was limited to the secondary and tertiary care institutions in the Western Province, in which a specialist physician is available. Prior to diagnosing a patient as COPD, the other probable disease entities giving rise to similar clinical features had been routinely excluded in all the settings. Hence, the investigators were convinced on the diagnosis made by the health staff led by the specialist physicians of the study settings.

The lower QOL may be due comorbid NCDs as well as the ongoing morphological pathologies in the body owing to COPD. They may be often experiencing 
respiratory symptoms and are anxious about their health. The lower QOL as well as worsening of it following an exacerbation are in par with worldwide evidence $(12,14)$. Only the pain domain did not show a significant reduction following exacerbation. Even in global literature, this remains an unexplained phenomenon, which needs further exploration in future research (29-30). According to some studies, pain is seemingly more in moderate COPD than in severe type (30). Furthermore, the presence of comorbidities has been identified as an independent predictor of higher pain (29). The presence of comorbid NCDs in our sample and at the same time, the exclusion of patients with conditions that were likely to influence their QOL, would have complicated the interpretation of nonsignificant reduction of the pain scores.

Pre-exacerbation QOL significantly correlated with better QOL after hospital discharge in relation to half of the domains. Better QOL would make the postdischarge QOL of them more favourable. However, this must be further explored using appropriate study designs. One limitation is the retrospective data collection on pre-exacerbation QOL. The influence of recall bias cannot be totally excluded in this regard, yet this strategy has been used in global literature (3132). Since exacerbations in COPD cannot be predicted precisely before its onset, retrospective data collection is the only option available. Additionally, it should be noted as a limitation that, there was a significant difference between the baseline QOL of responders and non-responders in relation to the role-limitationemotional domain of SF-36.

The patients who had a hospital stay less than 48 hours were excluded due to ethical reasons and to omit the unnecessary hospital admissions. However, this would have excluded some patients with lowered QOL and therefore, dilution of the findings. Another limitation is that when calculating the QOL, the eight domain scores were calculated only individually without performing the optional step of calculating the component scores. This was done as the Sri Lankan SF-36 coefficients are not available and owing to no universal agreement on the validity of these methods (33-34).

The lower income level was associated with lower pre-exacerbation QOL. Generally, it is stated that the 'poorest of poor has the worst health' which is termed as the 'social gradient' (35). This finding is comparative with some global literature and at the same time is contradictory to some $(3,36)$. Furthermore, this is compatible with the trend observed in Sri Lanka in which respiratory diseases are associated with the poor (9). To the contrary, a higher monthly income was associated with reduced post-discharge QOL. The subjective wellbeing of the survivors is likely to be less following exacerbations when the baseline economic status had been favourable. In other words, people living with better financial status experience a negative impact due to the exacerbation to a greater degree.

Better health infrastructure was associated with higher pre-exacerbation QOL. The role of the health infrastructure has been highlighted as an important social determinant of health (37), suggesting that higher availability, accessibility and affordability of health services are related to better baseline QOL. To the contrary, post-discharge QOL showed a significant reduction from the baseline when the pre-exacerbation health infrastructure was better. This highlights that though the health infrastructure is positively associated with baseline QOL, it does not cater to the demands following an exacerbation.

Gender has been documented as an influencing factor of QOL among COPD patients in literature. In contrast, in the current study, gender was not significantly influencing the QOL (3). This would have been made possible by the free health services in Sri Lanka and higher literacy irrespective of gender (38), enabling women to present to a health facility without additional delay compared to males. Furthermore, the established primary healthcare system enables accessibility to medical advices without any gender bias.

Lower severity of the exacerbation was associated with a lowered QOL compared to the baseline. One reason may be that the higher concern of the health staff and relatives about patients with a higher severity and the comparative neglect of those with lower severity. Secondly, the drastic impact following a severe exacerbation would have compelled them to perceive a better improvement at one month from hospital discharge.

Older age was associated with low pre-exacerbation QOL and a lowered QOL following exacerbation. This is noteworthy in relation to the ongoing demographic and epidemiological transition in Sri Lanka (9). 
More reforms are needed in the health system for enabling an elderly-friendly environment.

The present study describes several factors that were associated with the change in pre- and postexacerbation QOL. In addition, it identifies independent risk factors responsible for lowering the QOL following an exacerbation. Since previous literature on these aspects had been sparse, this study bridges a long awaited gap of scientific evidence. These findings could be used in prioritizing this entity among other chronic NCDs. After having tested the hypotheses with further studies, the independent risk factors could be used in deciding the frequency of follow up after hospital discharge. In addition, the findings could be used in describing the equity of health services and for policy planning on selecting patients for probable financial assistance schemes.

\section{Conclusions and Recommendations}

QOL among COPD patients was relatively low compared to other chronic NCDs. Younger age, higher income and better health infrastructure were associated with better QOL, which was found to worsen following an exacerbation. Older age, higher income level, better health infrastructure and less severity of the exacerbation were associated with a reduction in QOL following an exacerbation.

\section{Public health implications}

Patients with COPD are having a relatively lower QOL compared to patients with myocardial infarction and stroke. Their QOL is worsened with each exacerbation. Higher QOL is associated with improved levels of social determinants of health. Ensuring equity of healthcare would therefore improve their QOL and help in improving post-exacerbation QOL as well. Patients with relatively higher social determinants of health experience a higher reduction of QOL following exacerbations. Prioritizing needs of the patients following an exacerbation must be revisited. More attention must be paid to QOL of COPD patients in their management.

\section{Author Declarations}

Competing interests: The authors declare that they have no conflicts of interest

Ethics approval and consent to participate: Ethics approval was obtained from the Ethics Review Committee, Sri Lanka Medical Association (Reference No. ERC/14-019) and from Medical Research Institute (Reference No. 60/2014). Informed written consent was obtained from the participants.

\section{Funding: None}

Acknowledgements: Authors like to acknowledge the support given by all the Consultant Respiratory Physicians and the Consultant Physicians of the study settings.

Author contribution: PKB was the principal investigator and MW and SJ were supervisors. SM was involved in refining the methodology. JMSV and LSD were involved in data collection. All authors were involved in planning the analysis. PKB drafted the manuscript. All authors proof read and modified the article.

\section{References}

1. WHO. Chronic Respiratory Diseases-COPD. Geneva: World Health Organization, 2018.

Available from: http://www.who.int/respiratory/ copd/en/.

2. Lopez-Campos JL, Tan W, Soriano JB. Global burden of COPD. Respirology 2016; 21(1): 14-23.

3. Ståhl E, Lindberg A, Jansson S-A, Rönmark E, Svensson K, Andersson F, Lofdahl CG, Lundback B. Health-related quality of life is related to COPD disease severity. Health Quality Life Outcomes 2005; 3(1): 56.

4. Gerdtham UG, Andersson LF, Ericsson Å, Borg S, Jansson SA, Rönmark E, Lundback B. Factors affecting chronic obstructive pulmonary disease (COPD)-related costs: A multivariate analysis of a Swedish COPD cohort. European Journal of Health Economy 2009; 10(2): 217-226.

5. Wedzicha JA \& Seemungal TA. COPD exacerbations: defining their cause and prevention. Lancet 2007; 370: 786-796.

6. Gdg T \&, Ratio H. Management of exacerbations of COPD. Thorax 2004; 59(Suppl I): i131-156.

7. Burge S \& Wedzicha JA. COPD exacerbations: definitions and classifications. European Respiratory Journal 2003; 41(41 suppl): 46s-53s. 
8. Jayasekara RS \& Schultz T. Health status, trends and issues in Sri Lanka. Nursing \& Health Sciences 2007; 9(3): 228-233.

9. Engelgau M, Okamoto K, Navaratne KV, Gopalan S. Prevention and Control of Selected Chronic NCDs in Sri Lanka: Policy Options and Action. HNP Discussion Paper. Washington DC: World Bank, 2010.

10. WHO. Noncommunicable diseases: campaign for action - meeting the NCD targets: Sri Lanka profile. Geneva: World Health Organization, 2017.

Available from: http://www.who.int/beat-ncds/ countries/sri-lanka/en/.

11. WHOQOL Group. Development of the World Health Organization WHOQOL-BREF quality of life assessment. Psychological Medicine 1998; 28(3): 551-558.

12. Panos RJ, Krywkowski-Mohn SM, Sherman SN, Lach LA. Patient reported determinants of health: a qualitative analysis of veterans with chronic obstructive pulmonary disease. COPD 2013; 10(3): 333-347.

13. Corlateanu A, Siafakas N, Botnaru V. Defining COPD: from simplistic approach to multilateral assessment of COPD. Current Respiratory Care Reports 2012; 1(3): 177-182.

14. Solem CT, Sun SX, Liu S, Macahilig C, Katyal M, Gao $\mathrm{X}$, Shorr AF. Comparison of disease-severity measures within severe and very severe COPD patients: Results from a nationally representative chart review and patient survey. International Journal of COPD 2014; 9: 991-998.

15. Garratt A, Schmidt L, Mackintosh A, Fitzpatrick R. Quality of life measurement: bibliographic study of patient assessed health outcome measures. British Medical Journal 2002; 324(7351): 1417.

16. Ware JE, Snow KK, Kosinski M, Gandek B. SF-36 Health Survey. Manual and interpretation guide. Boston Mass: The Health Institute, New England Medical Center, 1993.

Available from: http://books.google.com/books/ about/SF_36_health_survey.html?id=WJsg AAAAMAAJ

17. Mallawarachchi DSV. Quality of life of stroke patients presenting to selected hospitals in the Colombo district and the possibility of common mental disorders among the principal informal caregivers. MD Thesis (Community Medicine). Colombo: Postgraduate Institute of Medicine, 2007.
18. Gunawardena NS, Seneviratne SRA, Atauda T. An approach to validation of a multi-dimensional tool. Journal of the College of Community Physicians Sri Lanka 2003; 8: 18-26.

19. Parshall MB, Mapel DW, Rice L, Williams A, O’Reilly J. Predictive validity of short-form health survey [36 items] scales for chronic obstructive pulmonary disease exacerbation. Heart Lung Journal Acute and Critical Care 2008; 37(5): 356-365.

20. Pickard AS, Yang Y, Lee TA. Comparison of healthrelated quality of life measures in chronic obstructive pulmonary disease. Health and Quality of Life Outcomes 2011; 9(1): 26.

21. DCS. Sri Lanka Census on Population and Housing 2012. Colombo: Department of Census and Statistics, 2012.

22. WHO. Diagnosis of COPD. Chronic Respiratiory Diseases. World Health Organization, 2017.

23. Charan J, Biswas T. How to calculate sample size for different study designs in medical research? Indian Journal of Psychological Medicine 2013; 35(2): 121-126.

24. Janjua NZ, Khan MI, Clemens JD. Estimates of intraclass correlation coefficient and design effect for surveys and cluster randomized trials on injection use in Pakistan and developing countries. Tropical Medicine and Internal Health 2006; 11(12): 1832-1840.

25. Mahesh PKB, Gunathunga MW, Jayasinghe S, Arnold SM, Mallawarachchi DSV, Perera SK, Wijesinghe UAD. Financial burden of survivors of medically-managed myocardial infarction and its association with selected social determinants and quality of life in a lower middle income country. BMC Cardiovascular Disorders 2017; 17(1): 251.

26. Mahesh PKB, Gunathunga MW, Jayasinghe S, Arnold SM, Liyanage SN. Factors influencing pre-stroke and post-stroke quality of life among stroke survivors in a lower middle-income country. Neurological Science 2018; 39(2): 287-295.

27. Mahesh PKB, Gunathunga MW, Jayasinghe S, Arnold SM, Haniffa R, De Silva AP. Pre-event quality of life and its influence on the post-event quality of life among patients with ST elevation and non-ST elevation myocardial infarctions of a premier province of Sri Lanka. Health and Quality of Life Outcomes 2017; 15(1): 154.

28. Feary JR, Rodrigues LC, Smith CJ, Hubbard RB, Gibson JE. Prevalence of major comorbidities in subjects with 
COPD and incidence of myocardial infarction and stroke: a comprehensive analysis using data from primary care. Thorax 2010; 65(11): 956-962.

29. HajGhanbari B, Holsti L, Road JD, Darlene Reid W. Pain in people with chronic obstructive pulmonary disease (COPD). Respiratory Medicine 2012; 106(7): 998-1005.

30. van Dam van Isselt EF, Groenewegen-Sipkema KH, Spruit-van Eijk M, Chavannes NH, de Waal MWM, Janssen DJA, Achterberg WP. Pain in patients with COPD: a systematic review and meta-analysis. British Medical Journal Open 2014; 4(9): e005898-e005898.

31. Failde II, Soto MM. Changes in health related quality of life 3 months after an acute coronary syndrome. BMC Public Health 2006; 6: 18.

32. Hofhuis JGM, Spronk PE, van Stel HF, Schrijvers AJP, Bakker J. Quality of life before intensive care unit admission is a predictor of survival. Critical Care 2007; 11(4): R78.

33. Laucis NC, Hays RD, Bhattacharyya T. Scoring the SF-36 in orthopaedics: a brief guide. Journal of Bone and Joint Surgery-American 2015; 97(19): 1628-1634.
34. Taft C, Karlsson J, Sullivan M. Do SF-36 summary component scores accurately summarize subscale scores? Quality Life Reasearch 2001; 10(5): 395-404.

35. WHO. World Conference on Social Determinants of Health: Meeting Report. Geneva: World Health Organization, 2011.

Available from: http://www.who.int/entity/ sdhconference/resources/Conference_Report. pdf?ua $=1$

36. Arne M, Lundin F, Boman G, Janson C, Janson S, Emtner M. Factors associated with good self-rated health and quality of life in subjects with self-reported COPD. International Journal of COPD 2011; 6(1): 511-519.

37. WHO. Closing the gap in a generation. Health equity through action on the social determinants of health. Final Report of the Commission on Social Determinants of Health. Geneva: World Health Organiation, 2008. Available from: http://www.bvsde.paho.org/bvsacd/ cd68/Marmot.pdf\%5Cnpapers2://publication/uuid/ E1779459-4655-4721-8531-CF82E8D47409

38. Medical Statistics Unit. Annual Health Bulletin 2014. Colombo: Ministry of Health, 2015. 